\title{
One Size Does Not Fit All: Organisational Diversity in New Zealand Tertiary Sector Ethics Committees
}

From their early beginnings in response to medical experimentation in Nazi concentration camps during World War II (enshrined in the 1947 Nuremberg Code) and reactions to the longitudinal Tuskegee Syphilis experiment 1932-1972 in the United States of America (USA), Institutional Review Boards - referred to in this paper as ethics committees- have taken on the role of monitoring biomedical research where participants might incur harm. However, concomitant with the growth of bureaucratic controls in research institutions (primarily universities), ethics committees have extended their mandate to embrace the ethics of social science research even when there is minimal risk of physical harm to participants (van den Hoonaard 2001).

While few would argue against the value of independent ethical review for any research project, a number of strong critiques warrant attention. The gradual encroachment of ethics committees into areas of research outside immediate biomedical concerns, dubbed 'mission creep' by critics of these developments (Haggerty 2004; White 2007), has raised fears among scholars that academic freedoms are being compromised. Increased surveillance of protocols has resulted in serious questions about the policing of appropriate methodology and suppression of methodological innovation (Ozdemir 2009), and has even led to the charge that ethics committees have become grammarians (Bauer 2000) whose primary concern is that applicants produce pristine paperwork. Cases have been reported where proposed studies have been declined on the basis of poor editorial work (Stark 2012) rather than a lack of rigour in considering the risks of harm to participants. Indeed, if pedantic attention to detail becomes the criteria for approval at the expense of rigorous researcher consideration of ethics, then ethics committees may come to 'undermine protection of human subjects' (Gunsalus et al. 2006, p. 1441). These concerns with detail on the one hand and extended policing of research proposals on the other, have seen committees accused of protecting the reputation of sponsoring institutions, what Iphofen (2009) labels research governance. One danger is that scholars have begun to seek ways of bypassing ethical review or developing satisficing practices that alienate them from the very system that is in essence designed to protect their interests and those of their participants (Bosk \& Devries 2004; Dingwall, 2008; Gunsalus et al. 2006; Hammersley \& Traianou, 2011)).

Since 1988 all university and funded health researchers in New Zealand have been mandated to subject their research proposals to ethics committees for formal ethics review. At the time the Ministry of Health ethics committees were guided by an Operational Standard for Health Research yet no equivalent National Ethics Statement (as found in Canada or Australia) has been produced to guide all University research in New Zealand. Ethics committees are part of the warp and weft of research university life in twenty first century Aotearoa New Zealand but we have had little public debate about the appropriate roles, practices and forms of university ethics committees. This paper seeks to initiate such a debate, beginning from the premise that whilst they are at the hub of research and academics are justifiably questioning of all institutions that appear to temper their autonomy unnecessarily, little is known about how they work. 
In our experience, the lack of secure knowledge about ethics committees reflects the diversity of protocols, practices and governance relations around which they take form in practice, often by developing incrementally around particular challenges in specific circumstances. Many work beyond the gaze of academics, or at least do not make fully clear their practices or invite external scrutiny, contributing to the impression that they meet in secret (Ashcroft \& Pfeffer 2001) or behind closed doors (Stark 2012). In the USA, Stark (2012 p.16) reports that applicants are invited to only $10 \%$ of ethics committee meetings. The international literature suggests that few social scientists have gained access to the inner sanctum (see de Jong et al. 2012; Fitzgerald 2005; Hedgecoe 2008; Stark 2012). Partly as a consequence, ethics committees have yet to be subjected to systematic research and appear wary of taking part in research in the face of consistent critique from social scientists, who are argued to be "angry and frustrated ..[that].. their work is being constrained and distorted by regulators of ethical practice who do not necessarily understand social science research” (Israel and Hay 2006, p. 1). As John O’Neill (2010, p. 229) observes in a memoir about his six years as a committee member and Chair at Massey University:

When I first read the call for writing about lived experiences of ethics review, I bristled. I feared that a request for stories of personal experience would solicit more polemics 'against the ethicists' on faceless committees who had supposedly misunderstood, hindered, distorted or otherwise prevented vital, well- designed educational research studies from taking place. This contribution attempts a corrective to such views by providing a personal narrative of human ethics committee membership (2003-2009) in a university setting that was largely positive and educative.

This article makes a first step in the New Zealand context to confront the problems created by the failure to ask what ethics committees actually do and to subject their practices to external scrutiny and constructive critique. It takes the novel form of asking five tertiary ethics committee members, two of them chairpersons, to provide details on how their committees work and thus engage in a first stage of dialogue. The outcome is unusual: although each of the committees operates on similar ethical principles their organizational shapes and operational practices vary. There is no national standard, arguably because different committees have taken the line that one size does not fit all. The aim of this paper is to lay out this difference and to ask what it tells us about transparency of process and the access of researchers to committees. Thus it is not an effort to either measure the effects of different practices or evaluate them directly. Rather, it is to ask whether attention to organisational form might point to a potential foundation for more ethical ethics committees and overcoming the suspicion that their responsibilities to foster ethical practice are being compromised by pedantry or overarching institutional interests.

The first part of the paper sets out invited commentaries from committee members four of the eight Aotearoa New Zealand Universities and one polytechnic that describe how their committees review applications. The second part takes the form of a discussion that builds on an analysis of key points in the committee process and levels of access to its decision making. Unsurprisingly, both commentaries from committee members and the jointly authored 
discussion that follows emphasise the merits of practices and seek to identify strengths of alternative approaches in particular circumstances. However, the reflection retains a critical edge centred on improving appropriate access and wider practices of the committees. As such, the paper walks the difficult edge between practitioner concern with best practice (in this instance that of ethics committees) and critical social science of what is an institution that regulates how (and even what) we come to know in universities.

\section{Massey University: A Traditional Centralised Ethics Committee that Admits Applicants}

I am the Chairperson of an ethics committee in a multi-centre New Zealand University. Each of the three centres has its own independent ethics committee that meets monthly reviewing between 15 to 20 applications from university staff and postgraduate students. One of these three committees reviews all health applications from all three campuses meaning all the applications reviewed by my committee are a mix of applications from social science and business. Low risk applications are reviewed by the central office. The committee I chair reviews only high risk applications.

The role of the Chair of the Committee outside monthly meetings is to assist applicants to refine their submission and then set the agenda for the forthcoming meeting. In the meetings, my role is to seek consensus in the discussions. Rarely does the committee vote on any decision. The twelve members, a mix of academics and four community representatives, have received written copies of applications some 7-10 days prior to each meeting. Like many ethics committees we use a lead reviewer and a secondary reviewer process although each member is expected to have read each application thoroughly.

From the outset of a meeting I expect each member will have adopted a position on each application based on their professional knowledge, research experience, and epistemology. Developing consensus, though, requires that committee members become flexible in revising their opinions about an application. Views change and initial judgements morph through discussion and debate. A recent example of this process occurred in response to a researcher who planned to observe young people working and playing in groups while at school. The committee's initial discussions were negative, deeming that observations of young people under the age of 16 would require multiple consents - parents, teachers, mentors and the students themselves - and gaining all of these approvals would make the research cumbersome and perhaps even impossible. Some members believed that if one student participant declined to participate, then the whole group observation would be jeopardised. Through lengthy debate and discussion with the applicant the committee came to a view that the observations were indeed low risk and would not impinge on the educational outcomes of students concerned. The applicant assured the committee that if a student (or parent) declined to be observed, the research could be conducted in other ways that still gave agency to the students. These assurances gave the committee confidence to approve the study.

This situation highlights that members are often protective of and concerned about areas of specific interest. For instance the members hold the privacy of all participants and the rights of 
individuals to decline as inviolate. Yet sometimes these concerns may obscure the intentions of a study such as the one just mentioned, which seeks to understand the behaviour of young people outside of normal classroom activities. Thus reaching consensus can be time-consuming and sometimes even difficult. Yet there is a will on the part of the members to find agreement.

While much of this practice is standard, this ethics committee is unusual in that it is open to both the public and researchers. While the public never attends, the provision opens a potential line of transparency ${ }^{1}$. Researchers are encouraged to attend and speak to their application. As Chair I find their attendance a rich learning resource for committee members and I would hope the researchers. Researchers in this case include not only tenure-track faculty members but also postgraduate students and their supervisors. Indeed, the Committee requires the supervisor to attend the meeting with their student. Some supervisors encourage their students to attend the meeting in order to capitalise on the educational potential. In many instances supervisors may speak for the student while the Committee wrestles with the application. Supervisor support is necessary as some of the conversations across the committee table can be rigorous and exacting. On occasions supervisors and students have been surprised and even shocked by the robustness of the discussion. A supervisor may contribute to the Committee's work by advocating for the student and his or her research proposal. These exchanges offer rich learning opportunities for researchers, students and committee members, and may help the inexperienced to develop clearer understandings of the ethical issues that the research provokes.

\section{Unitec: Lead Reviewer Corresponds with Applicant Prior to the Meeting}

I have served five years as a member of the Unitec research ethics committee, and am also an academic staff member at this tertiary institution. Our ethics committee reviews all research ethics applications across the Institute, for both faculty and postgraduate student projects, although projects involving medical interventions are referred to a Health and Disability ethics committee. Each month the committee, made up of an equal number of teaching staff and external (unaffiliated) members, meets to discuss, on average, ten high risk applications (and to note, or discuss as appropriate, negotiations and decisions surrounding any low-risk applications, for which only one reader is assigned).

Staff members submit all ethics applications: their own, and their students' - though students have written their applications by themselves in the vast majority of cases, with varied levels of supervision in the process. High risk applications are assigned a total of three readers: a primary reader and two secondary readers. Both academic and external persons take the lead role. Prior to the committee's monthly meeting, the two secondary readers post comments about applications on our institution's secure ethics committee web page, and the primary reader then composes feedback to the applicant (cc-d to any project supervisor).

\footnotetext{
${ }^{1}$ If members of the public were to attend, the committee has the provision to address sensitive issues in camera should these concern relationships between the committee and the University or involve socially or commercially sensitive research.
} 
Applicants are invited to respond to this provisional feedback prior to the meeting, so that their responses can be taken into account during the upcoming committee discussion. The committee encourages an engaged process of feedback with applicants and supervisors because ethical processes are not always intuitive. Much of the feedback is technical: 'please state that participants will be confidential, not anonymous', and 'please align withdrawal provisions throughout the application'. At times, however, the feedback is in the form of a developmental question: 'the readers consider that research into one's own counselling practice entails a conflict of interest, in that the researcher might be inclined to represent their practice in the most positive light possible. Can you please explain how you will mitigate against this possibility?' Or 'please detail your recruitment process within the participating schools so that the committee can be assured that no one who has line management duties in relation to a participant will know who accepts and who declines your invitation to participate'. Usually, the primary reader sends only one e-mail to the applicant prior to the committee meeting where the application will be discussed, and more often than not - I'd say in about $75 \%$ of cases - the applicant replies before the meeting date.

Applicants may, upon request to the Chairperson, attend the ethics meeting when their application is being discussed, but this opportunity is very rarely taken up (it has occurred once during my five years on the committee). The meetings are not open to the public. During the meetings, the primary reader presents the 'gist' of her or his assigned applications, along with the content of any applicant feedback received. The committee then discusses and debates any changes that are still required. Usually the sub-committee of readers have already covered the bulk of a given application's rough spots. The deeper institutional memory of the committee as a whole acts as a safeguard to errors or misunderstandings at the sub-committee stage, such as when a sub-committee missed the point that ethnographic observation in a public place did not require consent, whereas observation in a person's home did.

Following the meeting, the primary reader works with the applicant until the application is accepted or (rarely) declined. Often the process is straightforward, although not always quick. For example, I was primary reader for an application that initially wanted to obtain employee phone numbers from a company's CEO, but it took some time for the applicant to realise the need to protect employees' privacy. On other occasions, there can be extensive back-and-forth communication before an application is finalised, especially on those occasions when communication takes the form of heated e-mail exchanges about the appropriateness of the ethics committee's advice. These can often involve debates about academic freedom. While most are resolved in the usual round of post-meeting e-mails, a small number require phone consultations or face-to-face meetings. Some result in resolution through the exercise of committee powers or occasionally revisiting and modifying the role and scope of the ethics committee. Included in these cases are occasions when staff members of particular departments consistently object to ethics advice that is otherwise agreed-upon across the institution. In these cases, ethics presentations to the departments in question are arranged to discuss issues with staff and students.

\section{University of Canterbury: The Email Ethics Committee}


While I no longer serve on the University of Canterbury Human Ethics Committee (HEC), I served on the committee from 2002-2012 and was Chair from 2007-2012. In taking on the role of Chair I was aware that we had to institute a better process of review to ensure both researcher buy-in and a willingness of the best staff available to serve on the committee. In conversation with the then HEC administrator who also served as administrator for other committees I became aware of the processes followed by our Animal Ethics Committee: the (mainly) meeting-less committee.

In 2007, before taking up the position of Chair I called a committee meeting of all 12 committee members and outlined how I wanted the ethics committee to operate. I wanted the Human Ethics committee to be a meeting-less committee when it came to reviewing applications. There would be twice-yearly meetings to address matters of composition of the committee, changes to forms and necessary bureaucratic tidying. Monthly meetings to review applications would no longer be held. Instead the HEC would now operate an on-going review system wherein applications would be sent out to committee members on a rolling basis, when they came in to the Human Ethics secretary. Applications would then be circulated primarily by email, but some applications could be sent as paper copies for the minority who still wished to work on paper.

Committee members were to review applications within a two week period, between receiving them and returning their comments by email to the HEC secretary. As chair, my role was to review every application and make comments. At minimum comments from two-thirds of the committee i.e. eight of twelve ensured that feedback included comments from committee members within the college of the applicant, a Law-rep comment and a Maori-rep comment (where necessary). This meant that I also increased the size of the committee to ensure that every college in the university was represented and that we had two law representatives. I also made use of the ability of the Chair to second additional members as required.

The HEC secretary collated my comments and those from committee members. I would then meet with the secretary twice-weekly to collate a response to the applicant after reviewing all comments received. These requirements were then sent by email back to the applicant/s and they would in time send back, by email, a response and an amended application. I reviewed these, and if all points were met I would approve the application. This process reduced the time required for review and approval to less than one month on average. Most importantly, no longer were applicants tied to a set submission date or a fixed date for submitting revisions and responses. The changes also seemed to prompt an increased interest from academics in serving on the HEC, something I took to indicate support for the increased efficiency of the process.

A second change instituted at this time was to sort applications by risk. Not all applications required full review as many were of lower risk. As a result a low risk application form was created mainly for students at Masters level or below. These applications were reviewed first by the student's programme and then by the HEC Chair. Usually the Chair approved these low risk applications within a week. The success of this low risk, high risk system meant the committee extended this process to include low risk review for PhD students and staff. Operating under strict criteria for low risk research, these latter applications involved an initial review by the 
applicant's home programme, then by HEC Chair and members of the HEC rostered on a revolving list to ensure workloads were shared and kept manageable.

The low and high risk distinction and the meeting-less HEC had a number of positive effects. Unlike some ethics committees with a lay Chairperson (e.g. Otago), being an academic Chair I am on site and on-call throughout the week. In an average week I fielded 10-15 application inquiries; these included emails, phone calls and face-to-face meetings. These pre-application enquiries, from both staff and students, were invaluable as they smoothed the application process. In these consultations I would discuss the research and outline the ethical issues required. Anecdotally, I discovered that my increased availability worked to restore faith in the HEC. The number of applications received by the HEC increased, and I began to deal routinely with queries from researchers and students. The open-door/email/phone policy increased accessibility for researchers to the process, meant that amendments could be made efficiently, 'on the spot', and arguably fostered a new commitment to ethics review.

The new system represented a new philosophy. The HEC assumed all researchers wanted to be ethical. The roles of the HEC was to improve, not limit research. The aim was to work for a solution with researchers and to be pragmatic - yet ethical. As a result, very few applications were rejected. The high success rate was due to the level of pre-discussion undertaken with researchers. Therefore when an application came to the committee for review most of the difficult points had already been identified, discussed and worked through. The changes to our forms, and differentiating between high risk and low risk applications, were also crucial. The committee continually identified problems with the application form and made changes. Plus we collated a list of the common mistakes researchers made and in response made explicit related criteria in the application forms.

The success of the meeting-less ethics committee system was demonstrated when Canterbury suffered its series of 2010-2011earthquakes. The shutdown of the University, and the dislocation of departments, staff and HEC members did not stop the ethics review system. The meeting-less review system continued unimpeded and via phone-calls, emails and when necessary face-to face meetings with researchers. Even in these circumstances, the HEC system was able to succeed as normal. Researchers remained supportive of the system in place which meant that research and research review could continue as usual.

\section{Waikato University: A Devolved Ethics Review System}

This contribution tells three sides of the story of how devolved ethics committees operate at the University of Waikato. It begins with my role on the University's central Human Research Ethics Committee before describing how supervisors and their students interact with the devolved committee in the Faculty of Education. I also describe the submission of my $\mathrm{PhD}$ ethics application involving a sensitive topic. In the end I highlight some strengths of the devolved system over a more traditional homogenised ethics committee system. 
The University of Waikato utilises a system of devolved committees. The central Human Research Ethics Committee is an advisory committee to the Vice-Chancellor. Its membership is constituted by a chairperson appointed by the Academic Board; one academic staff member appointed by each of the seven Faculty Boards on the nomination of the Dean; one person (not a staff member) appointed by the University Council; one postgraduate student appointed by the Vice-Chancellor; and the possibility of co-opted members (University of Waikato 2013).

The Human Research Ethics Committee is responsible to the Academic Board for the promotion, review and monitoring of ethical practice in human research carried out by staff or students of the University and for monitoring compliance with the University's Human Research Ethics Regulations (University of Waikato 2013).

The ethical conduct in human research and related activities regulations (University of Waikato 2008) presents standards of ethical conduct and procedures for applying and monitoring these standards. As part of its responsibility the central committee has facilitated a series of university-wide ethics conversations to support development for ethics committee members, and for researchers and staff.

As a member on the central committee, I have been involved in the review of research proposals, reviewing a complaint, and making a contribution to the aforementioned ethics conversations. I liaise with the Faculty of Education Research Ethics Committee and report on committee matters to the Faculty of Education Board. The grist of regular ethical review of research applications, however, lies within the work of the devolved Faculty and School committees.

Every proposal for human research to be carried out by staff or students of the University must be referred to the relevant Faculty or School committee (or, where none exists, to the central University Human Research Ethics Committee). There are nine devolved committees (Arts \& Social Sciences; Computing \& Mathematical Sciences; Education; Law; Maori \& Pacific Development; Science \& Engineering; Psychology; Management; and Centre for Science and Technology Education Research) (University of Waikato 2013). The relevant faculty or school determines the membership of each committee.

Within the Faculty of Education at Waikato, the student's supervisor takes responsibility to liaise with the committee however the student prepares the application and submits it. Students are not invited to attend the ethics committee meeting, but are welcome to request, with their supervisor, to attend the ethics meeting with the committee. Generally, all communication stems from a designated committee member who speaks to the supervisor. The supervisor can request to speak to the committee or vice versa if there seems to be an issue that could be more easily worked through face-to-face but it is the exception rather than the rule. There is also an opportunity for the supervisor to clarify with a committee member any issue prior to the meeting. Many of our postgraduate students do not live locally so requiring attendance at committee meetings could be problematic.

My own recent experience of this devolved system is illustrative of the flexibility and openness built into the system, should a researcher wish to exercise it. My recent $\mathrm{PhD}$ project (see 
Flanagan 2013) explores social constructions of sexuality in childhood. The project involved interviewing teachers, counsellors and parents, inviting responses to a series of vignettes, and asking participants to provide any of their own stories about experiences of children whose actions have been perceived by adults as sexual. It also included interviews with primary school children. The topic is sensitive, and could extend any ethics committee's skills, as well as a concern for participant and institutional risk.

With a background in ethics, including formerly chairing one of the Health and Disability Ethics Committees, I sought an ethical review of my study based on consultation. My intention was to engage the committee in a dialogue about the ethical issues within and around my research rather than to achieve a 'ticked box' approval. I sought the conversation that considered the serious matters of people's lives and experiences, their relationships and identities at the core of my research. I wanted a substantial response that engaged with my study. I encountered a process that was respectful and dialogical. Including questions of care for me and how I was going to be practicing as a researcher, it became a discussion about how this project could go well rather than if it should go ahead or not.

The work of the devolved committees shifts concern from approval to the development of an application. For student applications, the committee is positioned as a group of consultants bringing their research expertise to the student's project. The committee responds to the supervisor in the first instance, and then with a letter that goes to the student. So the supervisor hears verbally soon after the meeting and has an understanding before the letter is received.

The Human Research Ethics Committee seeks to facilitate periodic “ethics conversations”, about three times each year. These conversations invite the wider research community at the University to think about the particular events or aspects of ethics that come up during research. Topics have included: ethics for research using digital technologies; issues around the use of incentives for participation in research; academic freedom, research methodology and ethics review; vulnerable populations and research; Māori research ethics: how different are they?; reporting of sensitive disclosures from research participants; storing data from research studies: privacy, security and reproducibility. These conversations are aimed to inform members of the ethics committees as much as researchers and to be a form of professional development around ethics review or ethical concerns.

\section{Auckland University of Technology: A Centralised Ethics Committee with Strong Advisory Focus}

The Auckland University of Technology Ethics committee (AUTEC) consists of up to seventeen members including a chairperson appointed by Council on recommendation of the Academic Board; one representative from each Faculty appointed by their Dean (Faculty representatives); an appointee of Council; an appointee of the Auckland University Student Movement; an appointee of the Pro Vice Chancellor Māori Advancement; an appointee of the Pro Vice Chancellor Research; and four to six other members co-opted by the Committee, the majority of whom are community representatives from outside the University. AUTEC's composition is 
tailored to ensure that it has appropriate medical, scientific and other research expertise. It aims to include at least one member who is a lawyer and at least two Māori members. Every member is appointed for a term of three years with the exception of the Executive Secretary whose membership is ex officio. The latter may attend meetings and vote on resolutions as an ordinary member of the Committee.

AUTEC meetings are presided by the Chair or their nominee. Meetings are non-public in order to safeguard intellectual property and commercial sensitivity. Together with the agenda the Chair assigns each application to a principal presenter. If possible, the Chair takes into consideration members' expertise and background. Faculty representatives are typically not assigned applications from within their own Faculty because they may have already provided feedback. Despite assignment of principal presenters, members are expected to have read all submissions. Hence, the burden of content presentation and comprehensive ethical considerations does not rest with one member only. Rather the principal presenter leads the discussion while other members agree or disagree with raised concerns and may add further issues. Applications are identified by presenters as either high or low risk, with high-risk applications tending to attract more debate.

As a Faculty representative on AUTEC, I represent my Faculty on fortnightly committee meetings and act to inform it where necessary in debates over issues specific to applications from within the faculty. I meet with the Executive Secretary bi-monthly to discuss any issues relating to their role, share information about new policies and guidelines, and consider new initiatives such as an on-line application system. I also represent AUTEC within the Faculty, advising applicants, explaining the committee’s decisions where necessary and organising outreach presentations and guest lectures.

This position embodies the tension produced by disciplinary difference in methodological traditions. Methodological differences between the Natural Sciences, Social Sciences and the Fine Arts keep committee members constantly learning, but conflicts are rare in practice given the commitments of all involved to ethical practice. Questions continually arise like: Does this auto-ethnography even require ethical approval since the only human participant is the researcher herself? Can eccentric muscle contractions be measured without inflicting pain on the research participant? These are debates devolved Ethics committees probably circumvent; yet, diverse perspectives are invaluable for cross-disciplinary applications.

Applicants are encouraged to discuss applications with their Faculty representatives prior to submission. Feedback may be provided electronically, via phone, or in person. Although consultation is not mandatory, the application form requires researchers to state whether they have sought advice. The question reminds applicants that support is available. The Committee recognises that applications written with assistance tend to be of higher quality, require less discussion time during the meeting, and are more likely to be approved without conditions or with only minor amendments. This increases the significance of Faculty representatives within the committee structure and emphasises the merits of the role, even though in practice there can be resistance to seeking or following advice, which cannot guarantee a successful application. The advisory role of the Faculty representatives is supplemented by the Ethics Secretariat's full 
time Ethics Advisor. The Advisor serves as an alternative contact and also a substitute for times Faculty representatives are on leave.

In making its decisions AUTEC uses a consensus model. While a voting system is in place, votes are rarely necessary as debate normally identifies sticking points and a potential resolution. Most applications are approved subject to a number of conditions which address major issues like lack of consultation with key stakeholders or minor problems like spelling mistakes in the participant information sheet. Once applicants have received the memorandum, they may either demonstrate that conditions have been met or provide specific reasons why certain conditions should not be met. Faculty representatives may assist in formulating these responses. After all conditions have been met or justly rejected, the Ethics Secretary to whom this responsibility is devolved grants final approval. The Secretary also approves modifications or alterations to previously approved applications which mostly concern time extensions or projects being withdrawn. Only about $6 \%$ of new applications are deferred, at which point two or three volunteering AUTEC members form a subcommittee which meets with the applicant during preparation of their resubmission.

\section{Discussion}

The commentaries above demonstrate clearly that although these ethics committees were established in the wake of the Aotearoa New Zealand Cartwright Inquiry held from 1987-1988 (Cartwright 1988) their formats are heterogeneous. No two committees share even broadly similar approaches in organizational structure (see Table 1). Four of the five ethics committees (Massey, Canterbury, Unitec and AUT) are centralised, but the way in which they operate differs significantly. AUT has incorporates representatives from each faculty into the central committee and devolves key advisory functions. The University of Canterbury operates a centralised ethics committee which meets via email. The Unitec ethics committee is centralised but operates in a distinctive collaborative style: the lead reviewer corresponds with applicants prior to the committee meeting. Massey University's ethics committee is a traditional centralised committee that meets monthly, but invites applicants to attend committee meetings. Waikato, on the other hand, devolves ethics review to the faculty level.

Table One about here

The narratives of committee organisation point to a number of issues with respect to committee organisation and practice, issues that shape the work of ethics committees, the ease and efficiency of the process for researchers and institutions, the nature of the outcomes of applications, and the levels of trust in the process. These include speed of approval, the role of lead reviewers, demarcating between high and low risk applications, workload for committee members, trade-offs between electronic and face to face processes, retaining institutional 
memory on committees, the process of feedback and access to advice, and the extent and nature of cross-disciplinary debate and provisions made to accommodate and resolve different ethical concerns and interpretations. That these are resolved differently by different committees in New Zealand points not only to the complexities of ethics review but a the multiple points at which suspicions about the process can arise. Each represents a potentially rich field for engaged debate among New Zealand social researchers.

One of the issues revealed in the narratives is that of access and transparency, which we highlighted above as crucial to the wider debates about the review process. The narratives confirm that greater transparency might be achieved in the work of ethics committees in New Zealand. Decisions are generally made in committee and by committees. While researchers do have a variable range of access to advice and to consultation, our collective experience suggests that they tend not to use the provisions that do exist. In fact, while the narratives only provide perspectives from within the committees and accounts of organisational structure, they point to a surprising level of access. Massey has provisions whereby researchers and the public can attend Committee meetings, while Waikato and Unitec allow researchers to attend them. Waikato's devolved structure facilitates access for both individual researchers and disciplinary interests, and promises applicants an opportunity to liaise with the lead reviewer after the meeting. Unitec provides for feedback from the lead reviewer to the applicant prior to the committee meeting, while AUT faculty representatives also have a pre-Committee consultative role that can allow researchers to seek advice and reviewers to seek clarification. These pre-committee engagements can stimulate a more informed debate within committee. Although University of Canterbury and Massey University's lead reviewers did not correspond with the applicant prior to the committee meeting both Chairpersons were adamant that they were willing and able to meet regularly with applicants prior to their submitting a full application. .

Our narratives do not allow us to comment on whether this access is effective in practice, or whether it can be represented as a transparent and open process for researchers. They do allow us, however, to recognise the variability of access and transparency and to suggest the need to explore why researchers appear not to take up these opportunities, or, if they do, whether in practice they provide for greater access and an improved experience.

To conclude, this paper suggests that the diversity of practice in itself is worthy of consideration, both as an empirical observation and as a field of contest. It suggests the consideration of the merits of greater standardisation of practice. This might offer the development of particular expertise and further refinement of a model fit for purpose in a New Zealand cultural, academic, and legislative context. With all committees struggling with similar issues, there are possibly grounds for suggesting such an approach. However, it is also clear from the narratives above that institutions have developed approaches that reflect their own institutional forms and research profiles. In fact, we believe that this has created systems that are locale-appropriate.

Perhaps the most significant dimension of the institutional specificity is size. For example, the two institutions not included among the five narratives are Auckland and Otago University. Logistically both Universities volume of ethics applications prohibits them adopting the open door approach described in Massey University narrative. Moreover, in 2013 both Otago and Auckland universities doubled the number of ethics committees from one to two each. The point being made here is that the ways in which 
ethics committees organise their review processes, and the philosophies that underlie them, are shaped by the workload demands placed on these structures. A commitment to 'immediate and personal attention' may be easier to execute when the number of applications is small.

Size of institution and workload alone, however, are not the only features of locale that condition ethics committee organization and practice. Waikato University, for example, has deep traditions of both Maori and feminist research and a tradition of devolved practice, which are all arguably reflected in the devolved structure of its ethics committee practices. Other committees have taken shape around particular faculty structures and moments in wider university reorganisation and reflect particular initiatives. The flexibility provided by the meeting-less Canterbury process, for example, has been validated and reinforced by the earthquake. Our point is again that ethics committees have been affected by the specificity of place and the way that is negotiated by different agents, such as the Canterbury Chair who initiated the meeting-less process.

Were Massey University ethics committee to increase its volumes from 20 to 80 applications per month this would severely curtail their open door policy. The point being made here is that the ways in which ethics committees organise their review processes, and the philosophies that underlie these are, to a large extent, determined by the work demands placed on these structures. Indeed we suggest that differences between committees are related to the differences in the size of the workloads in that 'immediate and personal attention' may be easier to execute when the number of applications is small

The attention to local specificity builds a level of responsiveness and reflexivity about the work of the ethics committees into their design, a responsiveness that we suggest strengthens ethical engagement. At Waikato University their devolved model means review of ethics applications is more likely close to peer review whereas at more centralised ethics committees insider knowledge is more diffuse. At AUT, ethics review is both devolved and diffuse. For example, "faculty representatives are typically not assigned applications from within their own Faculty because they may have already provided feedback.” An unanswered research question would ask does centralisation of ethics review contribute to the frustration that Israel and Hay highlight? That is, is the formalisation that is often associated with non-devolved systems perceived by applicants to be inflexible, unresponsive and slow. Moreover, the sense that ethics committees behave in a non-transparent way augments the disillusionment attributed to users of ethics review processes

Our narratives suggest that processes have been constructed to facilitate learning opportunities within the committees and in their exchanges with others. It is our firm view that New Zealand's ethics committees are far from a faceless body of experts who hand down decisions, and that this has been encouraged by the development of institution-specific approaches rather than a onesize-fits-all approach. While clearly a partial view, it is our view that developing case specific and locale-appropriate approaches has allowed for, if not fostered, dialogue and collegial engagement rather than enforcing compliance. The provisions described in these narratives allow for committees to educate and be educated by their constituents, even if we are unable to claim that this is the case in practice. 
514 This paper has sought to get inside what have heretofore appeared to be the inaccessible worlds

515 of ethics committees. We have presented a particular and partial reading of a set of narratives

516 about the organisation and practices of New Zealand ethics committees, which suggest that

517 researchers need to be mindful when discussing ethics committees in general that one size does

518 not fit all. One outcome of this research is that it has made ethics committees accessible. The

519 five narratives open a door, providing a benchmark for researchers, postgraduate students or

520 professional associations to survey researchers across institutions gauging researcher satisfaction

521 levels with different types of ethics review. While we recognise that there is a fundamental

522 tension existing between ethics committees and researchers, the preceding narrative attempts to

523 throw some light on the sources of these tensions and ways that some of this 'mistrust' might be

524 removed. Our hope is that these narratives will stimulate further empirical research on how they

525 are experience by researchers and foster more concerted debate. 


\section{References:}

Ashcroft R, Pfeffer N 2001. Ethics behind closed doors: do research ethics committees need secrecy? BMJ: British Medical Journal 322: 1294-1296.Bauer PE 2000. A few simple truths about your community IRB members. IRB 23: 7-8

Bosk, CL, De Vries, RG 2004. Bureaucracies of mass deception: Institutional review boards and the ethics of ethnographic research. The Annals of the American Academy of Political and Social Science, 595(1), 249-263.

Cartwright S. The Report of the Committee of Inquiry into allegations concerning the treatment of cervical cancer at National Women's Hospital and into other related matters. Auckland, New Zealand: Government Printing Office; 1988.

de Jong JP, van Zwieten MCB, Willems DL 2012. Ethical review from the inside: repertoires of evaluation in Research Ethics Committee meetings. Sociology of health \& illness 34: 10391052.

Dingwall, R. 2008. The ethical case against ethical regulation in humanities and social science research. Twenty-First Century Society, 3(1), 1-12.

Fitzgerald MH 2005. Punctuated equilibrium, moral panics and the ethics review process. Journal of Academic Ethics 2: 315-338

Flanagan P 2013. Ethical beginnings: Reflexive questioning in designing child sexuality research. Counselling and Psychotherapy Research 14: 139-146

Gunsalus CK, Bruner EM, Burbules NC, Dash L, Finkin M, Goldberg JP, Greenough WT, Miller GA, Pratt MG 2006. Mission creep in the IRB world. Science 312: 1441 http://www.ncbi.nlm.nih.gov/pubmed/16763114.

Haggerty KD 2004. Ethics creep: Governing social science research in the name of ethics. Qualitative Sociology 27: 391-414

Hammersley M. Traianou A (2011) Moralism and research ethics: a Machiavellian perspective. International Journal of Social Research Methodology 14(5) pp 379-390

Hedgecoe A 2008. Research ethics review and the sociological research relationship. Sociology 42: 873-886

Hoonaard WC 2001. Is Research-Ethics Review a Moral Panic?*. Canadian Review of Sociology/Revue canadienne de sociologie 38: 19-36

Iphofen R 2009. Ethical decision making in social research: A practical guide. Basingstoke, Palgrave Macmillan. 
Israel M, Hay I 2006. Research Ethics for Social Scientists, London, SAGE

O’Neill J 2010. One chairperson’s experience of ethical review: balancing principle, convention, relationship and risk in educational research. International Journal of Research \& Method in Education 33: 229-243.

Ozdemir V 2009. What to do when the risk environment is rapidly shifting and heterogeneous? Anticipatory governance and real-time assessment of social risks in multiply marginalized populations can prevent IRB mission creep, ethical inflation or underestimation of risks. The American Journal of Bioethics 9: 65-68

Rakowski CA 1993. The ugly scholar: Neocolonialism and ethical issues in international research. The American Sociologist 24: 69-86.

Stark L 2011. Behind closed doors: IRBs and the making of ethical research, Chicago, University of Chicago Press

White RF 2007. Institutional review board mission creep. The Independent Review XI (4): 547-64.

Waikato U 2014. Human Research Ethics Committee.

http://www.waikato.ac.nz/research/ro/ethics/human_ethics.shtml (accessed on 21 November 2013) 